\title{
O ATENDIMENTO EDUCACIONAL NO INTERIOR DA AMAZÔNIA: O MUNICÍPIO DE BELTERRA
}

\author{
Angela Rocha dos Santos ${ }^{1}$ \\ Maria Lília Imbiriba Sousa Colares ${ }^{2}$
}

\section{RESUMO}

O presente artigo aborda o tema da educação em um município amazônico pósemancipação à categoria de cidade, a partir da socialização de resultado de pesquisa desenvolvida pelo Programa de Pós-graduação Stricto Sensu em Educação, do Mestrado em Educação, na área de pesquisa em História, Política e Gestão Educacional na Amazônia da Universidade Federal do Oeste do Pará-UFOPA.Para este fim, buscou-se registrar um breve histórico sobre o atendimento da educação pública do Município de Belterra/PA, pautado pela compreensão da educação como política pública social. Os resultados demonstraram desafios educacionais a serem (re) pensados pelos gestores municipais, como a elevada taxa de analfabetismo, além de outras estatísticas de indicadores educacionais reveladores da exclusão do direito à educação e de aprendizagem, como evasão e reprovação. Neste sentido, podemos inferir que ainda o Estado Brasileiro, em especial, para a região amazônica, precisa implementar políticas educacionais que possam enfrentar os problemas de desigualdades, advindas de um processo histórico excludente do direito à educação. E, que apenas os Municípios isoladamente, não podem assumir unicamente.

Palavras-Chave: Educação Escolar; Políticas Educacionais; Município.

\section{THE EDUCATIONAL ATTENDANCE IN THE INTERIOR OF THE AMAZON: THE MUNICIPALITY OF BELTERRA-PA}

\begin{abstract}
This article addresses the issue of education in a post-emancipation Amazonian Municipality to category the city, from these arch result socialization developed by the postgraduate program in the strict sense in education, the Masters in Education, in the are a of research in History, Politics and Educational Management in theAmazon in the Federal Universityof Western Pará-UFOPA. Tothisend, we sought to register a brief history of the attendance of public education in the municipality of Belterra/PA, guided by the understanding of education as a social public policy. The results demonstrated educational challenges to be (re) designed by municipal managers, as the high rate ofilliteracy, in additiontoother educational indicators revealing statistics of exclusion of theright to education and learning, as tax evasionand disapproval. In this sense, we can in ferthat still the Brazilian State, in particular, for the Amazon region, need to implement educational policies that can address the problems of inequality, coming from a historical process that excludes the right to education. And, only the Municipalities in isolation, can not take only. Keywords: School Education; Educational Policies; Municipality.
\end{abstract}




\section{Introdução}

Este artigo trata sobre o contexto educacional do município de Belterra, estado do Pará, com apresentação de um panorama da educação escolar no município, considerando a periodização histórica de 1997 a 2012, a partir da socialização de dados gerais sobre o atendimento escolar e público municipal, indicadores educacionais, níveis de ensino e modalidades.

Assim sendo, destacamos a educação como política pública, pois entendemos que esta, seja concentrizada como direito a todos e dever do Estado, conforme disposto na Constituição Federal de 1988 e LDB (1996), neste cenário, apontamos a importância do papel dos municípios e os desafios para o cumprimento em prol do atendimento da educação escolar pública, respectivamente, por parte das suas secretarias municipais de educação, considerando a história da sociedade brasileira, de exclusão social e do acesso à educação.

Neste contexto, a presente pesquisa trata do tema das políticas educacionais em âmbito municipal, a partir da socialização de resultados de pesquisa de dissertação de Mestrado Acadêmico desenvolvido no Programa de Pós-graduação em Educação da UFOPA. A pesquisa teve como objeto de estudo a Secretaria Municipal de Educação (Semed) de Belterra, estado do Pará, com periodização de 1997 a 2012. Para fins deste artigo, apresentam-se o registro histórico da educação escolar municipal, pois entendemos a necessidade de "olharmos" para realidade escolar como um dos pressupostos para formulação, implementação e avaliação de políticas públicas e educacionais.

A investigação teve como base os pressupostos teórico-metodológicos da pesquisa qualitativa, sendo estudo como descritivo-analítico, a partir do registro histórico das políticas educacionais desenvolvidas pela Semed, no período investigado, pois compreendemos que pela natureza da pesquisa que "têm como objetivo primordial a descrição das características de determinada população ou fenômeno ou, então, o estabelecimento de relações entre variáveis". (GIL, 2002, p.42). Utilizamos como estratégia de pesquisa o estudo de caso, pois se trata de uma investigação empírica que "[...] investiga um fenômeno contemporâneo dentro de seu contexto da vida real". (YIN, 2001, p.32).

A periodização desta pesquisa de 1997 a 2012 é justificada por marcos históricos como: em âmbito nacional, o fato da aprovação em 1996, da nova LDB, lei no 9.394/1996, e suas orientações quanto ao Regime de Colaboração entre os Entes Federados, e atribuições quanto às competências aos Municípios para oferta educativa. Em âmbito local, por Belterra ter sido emancipada à categoria de município, com início do processo de eleições de governo em 1996 e início da primeira gestão municipal, em 1997, e o ano de 2012 por encerrar um ciclo de gestão municipal. O estudo foi iniciado com pesquisa bibliográfica, em seguida desenvolvido por pesquisa documental e de campo, por meio dos seguintes procedimentos metodológicos: análise documental (fontes documentais primárias e secundárias). E, entrevistas com aplicação de questionários aos (ex) secretários municipais de educação do período investigado.

O artigo está organizado em três partes. A primeira apresenta a caracterização do Município de Belterra, em seguida socializa-se a pesquisa desenvolvida, com destaque ao panorama da educação escolar. E, finaliza com considerações pertinentes ao tema em questão. 


\section{Caracterização do Município de Belterra/Pa}

Belterra, conhecida por seu peculiar patrimônio histórico-cultural e arquitetônico, foi criada em 1934, a partir de interesses político-econômicos, durante a vigência do Estado Novo do presidente Getúlio Vargas, por negociações entre o governador do estado do Pará, Dionísio Bentes (1926) e intermediários, em favor da instalação da Ford Motor Company (EUA)do empresário Henry Ford ${ }^{3}$ no Pará, além do interesse do Governo Federal. Em 1995, pela Lei Estadual 5.928, de 29 de dezembro de 1995, foi emancipado, tendo sido desmembrado do município de Santarém, com a mesma denominação. Sua instalação aconteceu em $1^{\circ}$ de janeiro de 1997.

Belterra é um município paraense (Figura 1), tem densidade demográfica (hab./km²) de 3,71 e conta com uma população estimada de 17.036 habitantes (IBGE/DPE/COPIS, 2015).

Figura 1-Mapa geográfico de localização de Belterra/PA

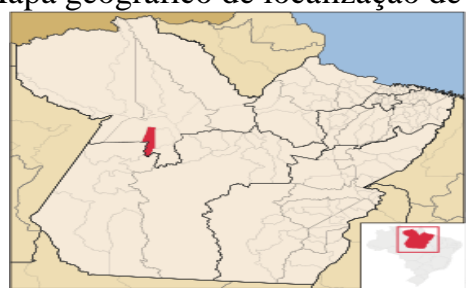

Fonte:http://www.ibge.gov.br/cidades/belterra.Acesso em 12.08.2014.

O município possui características eminentemente rurais, a maior parte do território de Belterra está na área rural, cujo território se divide em Floresta Nacional do Tapajós Flona (70\% da área), esta criada por Lei Federal em 1974, pelo antigo Instituto Brasileiro de Desenvolvimento Florestal (IBDF), atual Ministério de Meio Ambiente (MMA); Área de Preservação Ambiental do Aramanaí - APA (10\%), criada em 1995 por lei estadual; além de outra parte fora das áreas de preservação (trecho da Rodovia BR-163, SantarémCuiabá), correspondente a 10\%, segundo dados do Ministério das Cidades (2007) e IBGE (2010) e Pereira (2012). Ou seja, o município possui uma área rural aproximada de $90 \%$ e área urbana de $10 \%$ do seu território, com áreas de proteção e preservação ambiental e florestal, o que lhe confere a necessidade e possibilidade de ações estratégicas a serem pensadas para o desenvolvimento sustentável.

O contexto das populações do campo do município possui como uma de suas características, a presença de aldeias indígenas ${ }^{4}$ em processo de reconhecimento considerando o período até 2012. Porém, para fins educacionais, estas áreas, já são reconhecidas como tais pela Secretaria Estadual de Educação do Pará (Seduc) e Secretaria Municipal de Educação de Belterra, sendo declaradas no censo escolar do Inep. (COLARES, 2013). Neste sentido, dentro da área territorial da Flona do Tapajós, têm-se três comunidades que se assumiram como aldeias indígenas: Takuara, Marituba e Bragança.

Ao verificarmos a situação de indicadores socioeconômicos, temos os seguintes dados: o município de Belterra apresenta $47,03 \%$ de pobres, com $28,50 \%$ de extremamente pobres (2010), apresentando uma diminuição após uma década (2000). De acordo com o PNUD/Ipea/FJP (2010), Belterra ocupa a $4.444^{\mathrm{a}}$ posição entre os 5.565 municípios brasileiros, segundo o Índice de Desenvolvimento Humano (IDHM). Nesse ranking, o maior IDHM é 0,862 (São Caetano do Sul/SP) e o menor é 0,418 (Melgaço/PA). A dimensão que mais contribui para o IDHM do município é Longevidade, com índice de 
0,775, seguida de Renda, com índice de 0,548, e de Educação, com índice de 0,478, segundo dados do PNUD/Ipea/FJP/Atlas 2013.

\section{Panorama da Educação Escolar em Belterra/PA}

Os dados apresentados neste item são advindos de fontes documentais, como documentos e relatórios estatísticos, de domínio público, disponíveis em sites como Fapespa, Idesp/Sepof/Seduc/PA, Inep, Censos Escolares/ Inep, IBGE, Atlas do PNUD, Observatório do PNE, Todos pela Educação, Qeduc.org. e dados.gov.br. Foram obtidos, também, dados de relatórios e registros de atividades desenvolvidas, disponibilizados pela Semed. Outras fontes utilizadas são produções acadêmicas como dissertações e artigos sobre o município ${ }^{5}$, bem como livros, matérias de jornais, blogs e textos de pesquisadores sobre a história da cidade. Para fins de construir o panorama da educação municipal, utilizaram-se também, como dados, fontes orais, como depoimentos de (ex-) servidores da Semed, no sentido de apresentar dados sobre a educação escolar municipal.

A seguir, voltamos à atenção para o atendimento escolar, considerando o período de 1997 a 2012.

\section{Atendimento escolar pós-emancipação}

Após a emancipação de Belterra, no final de 1995, a rede de ensino público municipal neste ano e em 1996 ainda era de responsabilidade da Secretaria de Educação, Cultura e Desporto de Santarém (Prefeitura Municipal de Santarém), fase intermediária justificada pelo momento de transição de governança, à espera da eleição da primeira gestão municipal. Em 1997 é empossado o primeiro prefeito de Belterra e a administração da educação escolar pública municipal torna-se de responsabilidade da Secretaria Municipal de Educação (Semed) de Belterra. Quanto à rede estadual de ensino, esta continua de responsabilidade da $5^{a}$ Unidade Regional de Ensino da Secretaria Estadual de Educação do Pará (5a URE/Seduc).

Quanto à oferta da educação básica em Belterra, da rede pública municipal, estadual e particular, temos as seguintes informações, conforme a Tabela 1, do período de 1997-2012.

Tabela 1- Número de estabelecimentos, matrículas, docentes e turmas - 1997-2012

\begin{tabular}{lllll}
\hline Ano & Estabelecimentos & Matrículas & Docentes & Turmas* \\
\hline 1997 & 43 & 3.096 & 99 & - \\
1998 & 60 & 3.486 & 146 & - \\
1999 & 57 & 3.859 & 171 & - \\
2000 & 57 & 4.300 & 178 & - \\
2001 & 54 & 4.275 & 149 & - \\
2002 & 59 & 4.387 & 178 & - \\
2003 & 59 & 4.452 & 182 & - \\
2004 & 64 & 4.567 & 175 & - \\
2005 & 65 & 4.760 & 211 & - \\
2006 & 69 & 5.127 & 208 & - \\
2007 & 71 & 5.715 & 185 & 271 \\
2008 & 69 & 5.510 & 211 & 283 \\
2009 & 73 & 5.759 & 219 & 310 \\
2010 & 70 & 6.074 & 251 & 355 \\
2011 & 70 & 5.849 & 253 & 341 \\
2012 & 71 & 5.940 & 256 & 356 \\
\hline
\end{tabular}


Fonte: Observatório PNE. Estatística Municipal Belterra/Idesp/Sepof (2014). MEC/Inep/DEED/Censo Escolar. Disponível em: <http://portal.inep.gov.br/indicadoreseducacionais〉. Acesso em: 04.12.2014.

* Ressalta-se que os dados sobre média de alunos/turma de 1997 a 2006 não estão passíveis de identificação, até a extração para fins desta pesquisa, no site do Inep. Apenas, dados referentes à UF (Pará) e não por localidades. A partir de 2007, há a disponibilização dos dados pelo INEP.

Na Tabela 1, observa-se que no ano de 1997 o atendimento escolar do município era de 43 estabelecimentos (dependência estadual, municipal e particular), com oferta da educação infantil, ensino fundamental e ensino médio, num total de 3.096 matrículas e 99 docentes, ao passo que no ano seguinte (1998) houve um aumento de 18 estabelecimentos, com ampliação de 390 novas matrículas, num total de 3.486 matrículas. Dentre as justificativas possíveis deste aumento identifica-se a municipalização do ensino em Belterra, ocorrida em 1998, com repasse de estabelecimentos da rede estadual para a rede pública municipal, além de novos estabelecimentos.

Identifica-se na Tabela 1 que nos anos de 2007 e 2009 houve uma ampliação no quantitativo de estabelecimentos, respectivamente, entre 71 e 73 , bem como elevação no número de matrículas; porém, observa-se um quantitativo baixo no número de docentes por turmas, o que permite inferir um dado instigante quanto à realidade educacional local, especificamente, a presença da organização de turmas de ensino multisseriado para unidocentes, ou seja, 1 docente para 2 ou mais séries/anos do ensino fundamental. Percebese que a oferta do ensino multisseriado é uma das principais características da rede pública municipal. Retomaremos esta discussão no decorrer deste trabalho.

Quanto aos dados referentes às dependências administrativas por nível de ensino, temos as seguintes informações:

Tabela 2- Dados sobre número de estabelecimentos por Administração/Nível de Ensino - Intervalo entre gestões municipais de 1997-2012

\begin{tabular}{|c|c|c|c|c|c|c|}
\hline \multirow[b]{2}{*}{ Anos } & \multirow[b]{2}{*}{ Nível } & \multicolumn{5}{|c|}{$\mathbf{N}^{\mathbf{o}}$ de Estabelecimentos } \\
\hline & & Federal & Estadual & Municipal & Particular & Total \\
\hline \multirow{3}{*}{1997} & Pré-escolar & - & - & 1 & - & 1 \\
\hline & E. Fundamental & - & 5 & 36 & - & 41 \\
\hline & E. Médio & - & 1 & - & - & 1 \\
\hline \multirow{3}{*}{2000} & Pré-escolar & & - & - & - & - \\
\hline & E. Fundamental & - & - & 56 & - & 56 \\
\hline & E. Médio & - & 1 & - & - & 1 \\
\hline \multirow{3}{*}{2001} & Pré-escolar & - & - & - & - & - \\
\hline & E. Fundamental & - & - & 53 & - & 53 \\
\hline & E. Médio & - & 1 & - & - & 1 \\
\hline \multirow{3}{*}{2004} & Pré-escolar & - & - & 3 & - & 3 \\
\hline & E. Fundamental & - & - & 57 & - & 57 \\
\hline & E. Médio & - & 1 & - & - & 1 \\
\hline \multirow{3}{*}{2005} & Pré-escolar & - & - & 4 & 1 & 5 \\
\hline & E. Fundamental & - & - & 59 & - & 59 \\
\hline & E. Médio & - & 1 & - & - & 1 \\
\hline \multirow{3}{*}{2008} & Pré-escolar & - & - & 12 & - & 12 \\
\hline & E. Fundamental & - & - & 62 & - & 62 \\
\hline & E. Médio & - & 1 & - & - & 1 \\
\hline \multirow{3}{*}{2009} & Pré-escolar & - & - & 18 & - & 18 \\
\hline & E. Fundamental & - & - & 62 & - & 62 \\
\hline & E. Médio & - & 1 & - & - & 1 \\
\hline \multirow{3}{*}{2012} & Pré-escolar & - & - & 22 & 1 & 23 \\
\hline & E. Fundamental & - & - & 58 & 1 & 59 \\
\hline & E. Médio & - & 1 & - & 1 & 2 \\
\hline
\end{tabular}


Fonte: Estatística Municipal Belterra/Idesp/Sepof (2014). MEC/Inep/DEED/Censo Escolar.

Na Tabela 2 verifica-se que o município, entre 1997 a 2012, não possuiu escolas de dependência administrativa da rede federal de ensino. Em relação ao atendimento escolar pela rede estadual, observa-se apenas 1 estabelecimento escolar para oferta do ensino fundamental, apenas em 1997, e ensino médio regular, durante os demais anos do período investigado. O estabelecimento localiza-se na área urbana do município.

Em relação ao atendimento escolar da rede pública municipal, destaca-se a predominância da oferta do ensino fundamental, com 37 estabelecimentos, sendo 1 para oferta de educação infantil e 36 para o ensino fundamental, em 1997. No final do período investigado (2012), constata-se o número de 88 estabelecimentos escolares para oferta de educação infantil (22) e no ensino fundamental (58), o que permite inferir a atribuição da responsabilidade e obrigatoriedade do poder público perante esta oferta à população. Porém, tem-se que o atendimento escolar para oferta da educação infantil (pré-escolar) teve quantitativo em 1997 (3 estabelecimentos) e depois em 2004 a 2012, com ampliação no último ano de 22 estabelecimentos, estes de responsabilidade da Secretaria Municipal de Educação (Semed).

Quanto à rede de ensino particular, na Tabela 2, verifica-se que o início de atendimento ocorreu em 2005 com 1 estabelecimento, com oferta de educação infantil (pré-escola), e ao final de 2012 há 3 estabelecimentos: 1 para atendimento de educação infantil (pré-escola), 1 de ensino fundamental e 1 para oferta do ensino médio.

Destacamos a seguir o atendimento escolar público em Belterra, considerando dados referentes à rede pública de ensino estadual e municipal, com atenção à oferta educativa por parte da rede municipal de ensino, sob responsabilidade da Semed.

\section{Atendimento escolar público}

Para fins de comparativo sobre a educação escolar pública em Belterra, diante do contexto educacional mais amplo do país, entre o ano de 1997 e 2012, apresentamos dados sobre o número de matrículas em nível nacional, regional, estadual e municipal.

Tabela 3 -Número de matrículas totais* - Rede Pública - Brasil/Região Norte/Pará/Belterra - 1997/2012

\begin{tabular}{c|c|c}
\hline \multirow{2}{*}{ Ano } & Unidades da Federação & $\mathbf{N}^{\mathbf{0}}$ de Matrículas* \\
\hline \multirow{4}{*}{1997} & Brasil & 40.634 .445 \\
\cline { 2 - 3 } & Região Norte & 2.604 .845 \\
\cline { 2 - 3 } & Pará & 1.920 .472 \\
\cline { 2 - 3 } & Belterra & 3.096 \\
\cline { 2 - 3 } & Brasil & 42.222 .831 \\
\cline { 2 - 3 } & Região Norte & 4.563 .628 \\
\cline { 2 - 3 } & Pará & 2.220 .962 \\
\hline \multirow{3}{*}{2012} & Belterra & 5.282 \\
\hline
\end{tabular}

Fonte:<http://portal.inep.gov.br/basica-censo-escolar-sinopse-sinopse>. Acesso em: 12.08. 2015. Elaborado pela autora (2015).

Dados estimados, considerando os dados da fonte pesquisada.

Legenda NIF - Não identificado nas fontes.

Destaca-se que o atendimento público em Belterra corresponde à realidade do estado do Pará, quanto a um número significativo de matrículas na área rural. Em relação ao atendimento escolar público em Belterra, apresentam-se os seguintes dados da rede municipal de ensino, na Tabela 04. 
Tabela 41 - Levantamento simplificado sobre atendimento escolar público - Municipal - Intervalo entre $1997 / 2012$

\begin{tabular}{c|c|c|c|c}
\hline \multirow{2}{*}{ Anos } & \multirow{2}{*}{ Nível } & \multicolumn{3}{|c}{ Municipal } \\
\cline { 2 - 5 } & \multirow{3}{*}{$\mathbf{1 9 9 7}$} & $\mathbf{N}^{\mathbf{0}}$ de Escolas & $\mathbf{N}^{\mathbf{0}}$ de Docentes & $\mathbf{N}^{\mathbf{0}}$ de Matrículas \\
\cline { 2 - 5 } & Ed. Infantil (Pré-escola) & 1 & 2 & 65 \\
\cline { 2 - 5 } & E. Fundamental & 36 & 91 & 2.863 \\
\hline \multirow{3}{*}{$\mathbf{2 0 1 2}$} & E. Médio & - & - & - \\
\cline { 2 - 5 } & Ed. Infantil* & 22 & NIF & 642 \\
\cline { 2 - 5 } & E. Fundamental & 58 & - & - \\
\hline
\end{tabular}

Fonte: Estatística Municipal/Idesp/Sepof (2014); Censo Escolar/INEP/Sistema Gestor da Semed (2010, 2011, 2012).

Elaborado pela autora (2015).

* Educação Infantil (Pré-escola e Creche).

Na Tabela 4 são apresentados dados simplificados do período entre 1997 e 2012, pois na próxima seção retomaremos os dados dos demais períodos, conforme o intervalo das gestões municipais. Percebe-se, que houve a expansão da rede pública municipal entre 1997 e 2012, quanto ao número de escolas, matrículas e de docentes. A rede municipal possuía em 1997 um total de 37 estabelecimentos, sendo 1 para educação infantil e 36 para o ensino fundamental, e 93 docentes e 2.968 matrículas para oferta total entre educação infantil (pré-escola) e ensino fundamental, sem número de creches. Em 2012, a sua rede apresentava 80 estabelecimentos, 201 docentes (ensino fundamental), 642 matrículas na educação infantil (creche e pré-escola) e 3.878 matrículas para ensino fundamental. Destaca-se a oferta da rede municipal de educação infantil em creches municipais entre 2004 a 2012.

Ao buscarmos informações quanto ao número de bibliotecas escolares e laboratórios de informática na rede pública municipal, obtivemos dados, de acordo com o Idesp/Sepof (2014), de que entre 1997 e 1998 não havia informação sobre escolas com biblioteca e com laboratório de informática, sendo de 1999 o primeiro de 1 biblioteca escolar. No período de 2007 a 2009 ocorreu uma ampliação, com quantitativo de total de 10 bibliotecas escolares, e redução entre 2010 a 2012, respectivamente, 8, 8 e 7. Quanto aos laboratórios de informática, a rede municipal possuía 1 laboratório em 2008, ao passo que em 2012 já existia o total de 7 laboratórios, com apenas 2 escolas com acesso à Internet, de acordo com o diagnóstico socioeconômico da Fapespa (2015) e Idesp/Sepof (2014).

Adiante, apresentamos dados relacionados à elevação e distribuição de matrículas por nível de ensino.

\section{Elevação e distribuição de matrícula por nível de ensino} a) Nível de ensino: educação infantil

A educação infantil tem sido pautada, a partir da CF 1988, Lei 9.393/1996 (LDB), do Referencial Curricular para Educação Infantil (1998), da Política Nacional da Educação Infantil (1994), das Diretrizes Curriculares Nacionais para Educação Infantil, aprovada e fixada pela Resolução 5, de 17 de dezembro de 2009, dentre outros documentos norteadores da educação brasileira, como o Plano Nacional de Educação. No teor da lei, as crianças passam a ser consideradas como sujeitos de direitos, com exigência da atenção por parte do poder público, quanto ao atendimento deste nível de ensino, considerando os princípios da educação infantil do "cuidar, educar e brincar", suas especificidades, objetivos, tempos e espaços. 
$\mathrm{Na}$ LDB, Lei 9.394/1996, a educação infantil é considerada primeira etapa da Educação Básica, a ser oferecida em creches, para crianças de zero a 3 anos, e em préescolas, para crianças de 4 e 5 anos, e está sob a responsabilidade prioritariamente do poder público municipal, integrando o sistema municipal de ensino, junto com o ensino fundamental (Lei 9394/96 - LDB). Tais documentos legais tornaram-se referências para uma política nacional, voltada para educação infantil.

Abreu (2004) analisa que a nova legislação educacional marcou uma mudança em relação ao papel do Estado, passando-se a atenção ao educar e cuidar, permitindo, desta forma, segundo Saviani (2011), possibilidades de avanços dos objetivos proclamados quanto aos direitos. Neste caso, quanto ao direito das crianças à educação e quanto à atenção pelas políticas públicas para o exercício de sua cidadania, em termos legais.

Quanto aos dados sobre o contexto de Belterra, sobre a matrícula por dependência administrativa e graus de ensino publicado no Relatório da Idesp/Sepof/Seduc, o período de 1997-2012 apresenta dados sobre a Educação Infantil (pré-escola), conforme Tabela 5, os seguintes dados:

Tabela 52 - Matrícula por dependência administrativa e nível de ensino - Educação Infantil - 1997-2012

\begin{tabular}{|c|c|c|c|c|c|}
\hline \multirow[t]{2}{*}{ Anos/ Nível } & \multicolumn{5}{|c|}{ Matrícula } \\
\hline & Federal & Estadual & Municipal & Particular & Total \\
\hline 1997 & - & - & 65 & - & 65 \\
\hline 1998 & - & - & - & - & - \\
\hline 1999 & - & - & & - & - \\
\hline 2000 & - & - & - & - & - \\
\hline 2001 & - & - & & - & - \\
\hline 2002 & - & - & & - & - \\
\hline 2003 & - & - & - & - & - \\
\hline 2004 & - & - & 74 & - & 74 \\
\hline 2005 & - & - & 106 & 7 & 113 \\
\hline 2006 & - & - & & & \\
\hline 2007 & - & - & & & \\
\hline 2008 & - & - & 335 & - & 335 \\
\hline 2009 & - & - & & & \\
\hline 2010 & - & - & & & \\
\hline 2011 & - & - & 421 & 11 & 432 \\
\hline 2012 & - & - & 490 & 31 & 521 \\
\hline
\end{tabular}

Fonte: MEC/Inep/Seduc.

Elaboração: Idesp/Sepof (2014).

$\mathrm{Na}$ Tabela 5, atenta-se para a ausência de registro na estatística oficial da Idesp/Sepof, que tem por fonte o Inep/Mec/Seduc, de modo que nos anos de 1998 a 2003 não houve dado informado por parte do município acerca das crianças matriculadas na educação infantil (pré-escolar e/creche), o que revela ser um dado instigante quanto aos dispositivos legais relacionados à oferta deste nível de ensino e ao direito das crianças.

\section{b) Nível de ensino: ensino fundamental}

O ensino fundamental é considerado como nível de ensino da educação básica e, após a CF 1988 e LDB 9.394/1996, de oferta obrigatória e de direito subjetivo (assim expresso na LDB), sendo alterado, entre 1997 a 2012, de oito anos para nove anos, tendo por objetivo a formação básica do cidadão, conforme art. 32 da LDB e incisos (BRASIL, 1996), mediante

I - o desenvolvimento da capacidade de aprender, tendo como meios básicos o pleno domínio da leitura, da escrita e do cálculo; 
II - a compreensão do ambiente natural e social, do sistema político, da tecnologia, das artes e dos valores em que se fundamenta a sociedade;

III - o desenvolvimento da capacidade de aprendizagem, tendo em vista a aquisição de conhecimentos e habilidades e a formação de atitudes e valores;

IV - o fortalecimento dos vínculos de família, dos laços de solidariedade humana e de tolerância recíproca em que se assenta a vida social.

Durante a história da educação brasileira, houve medidas para ampliação dos anos do ensino fundamental, conforme os dados da Secretaria de Educação Básica (SEB), do MEC, quanto o registro histórico do ordenamento político-legal, apresentado, a seguir:

Acordo Puntadel Leste e Santiago - Compromisso de estabelecer seis anos para o Ensino Fundamental até 1970; Lei $\mathrm{n}^{\circ}$ 5.692, de 11 de agosto de 1971 - Obrigatoriedade do Ensino Fundamental de oito anos; Lei ${ }^{\circ} 9.394$, de 20 de dezembro de 1996 - admite a matrícula no Ensino Fundamental de nove anos, a iniciar-se aos seis anos de idade; Lei $n^{\circ} 4.024$, de 20 de dezembro de 1996 - Estabelecia 4 anos de Ensino Fundamental; Lei no 10. 172, de 9 de janeiro de 2001, que aprovou o Plano Nacional de Educação/PNE. O Ensino Fundamental de nove anos se tornou meta progressiva da educação nacional; Lei $\mathrm{n}^{\circ} 11$. 114, de 16 de maio de 2005 - torna obrigatória a matrícula das crianças de seis anos de idade no Ensino Fundamental; Lei ${ }^{\circ}$ 11.274, de 6 de fevereiro de 2006 - amplia o Ensino Fundamental para nove anos de duração, com a matrícula de crianças de seis anos de idade e estabelece prazo de implantação, pelos sistemas, até 2010. (BRASIL, 2015).

Em relação à elevação e distribuição de matrículas no ensino fundamental, no período investigado, identificamos os seguintes dados, conforme Tabela 6:

Tabela 6 - Matrícula por dependência administrativa e nível de ensino - Ensino Fundamental - 1997-2012

\begin{tabular}{|c|c|c|c|c|c|}
\hline \multirow[b]{2}{*}{ Anos } & \multicolumn{5}{|c|}{ Matrícula } \\
\hline & Federal & Estadual & Municipal & Particular & Total \\
\hline 1997 & - & 1.158 & 1.705 & - & 2.863 \\
\hline 1998 & - & - & 3.268 & - & 3.268 \\
\hline 1999 & - & - & 3.641 & - & 3.641 \\
\hline 2000 & - & - & 3.857 & - & 3.857 \\
\hline 2001 & - & - & 3.771 & - & 3.771 \\
\hline 2002 & - & - & 3.899 & - & 3.899 \\
\hline 2003 & - & - & 3.958 & - & 3.958 \\
\hline 2004 & - & - & 4.044 & - & 4.044 \\
\hline 2005 & - & - & 4.153 & - & 4.153 \\
\hline 2006 & - & - & 4.341 & - & 4.341 \\
\hline 2007 & - & - & 4.154 & - & 4.154 \\
\hline 2008 & - & - & 4.077 & - & 4.077 \\
\hline 2009 & - & - & 3.947 & - & 3.947 \\
\hline 2010 & - & - & 4.034 & - & 4.034 \\
\hline 2011 & - & - & 4.020 & 13 & 4.033 \\
\hline 2012 & - & - & 3.878 & 20 & 3.898 \\
\hline
\end{tabular}

Fonte: MEC/Inep/Seduc.

Elaboração: Idesp/Sepof (2013).

Na Tabela 6 verifica-se que a rede estadual teve o número de matrículas, total de 1.158, apenas em 1997. Ao passo que na rede municipal, entre 1997 a 2000, houve maior 
elevação no número de matrículas, decorrente do processo de municipalização da educação, ocorrido em 1998, após assinatura do Convênio 020/1998 com a SEDUC para adesão à municipalização do ensino.

Quanto aos dados referentes às taxas de rendimento escolar de 1997 a 2012, dos anos iniciais e finais do ensino fundamental da rede pública de ensino, temos os seguintes dados:

Tabela 7 -Taxas de Rendimento Escolar - Ensino Fundamental - 1997-2012 -Intervalo de gestões municipais

\begin{tabular}{lllllll}
\hline \multirow{2}{*}{ Anos } & \multicolumn{2}{l}{ Anos Iniciais do Ensino Fundamental } & \multicolumn{3}{l}{ Anos Finais do Ensino Fundamental } \\
\cline { 2 - 7 } & Aprovação & Reprovação & Abandono & Aprovação & Reprovação & Abandono \\
$\mathbf{1 9 9 7}$ & 68,6 & 10,7 & 20,7 & 97,8 & - & 2,2 \\
$\mathbf{2 0 0 0}$ & 76,4 & 7,9 & 15,7 & 90,2 & 4,1 & 5,7 \\
$\mathbf{2 0 0 4}$ & 77,2 & 13,8 & 9 & 81,7 & 13,5 & 4,8 \\
$\mathbf{2 0 0 5}$ & 78,5 & 15,1 & 6,4 & 90,7 & 5,6 & 3,7 \\
$\mathbf{2 0 0 8}$ & 66,7 & 27,3 & 3,9 & 72,4 & 18,4 & 7,6 \\
$\mathbf{2 0 1 2}$ & 82,2 & 13,8 & 0,7 & 84,9 & 12,1 & 1,7 \\
\hline
\end{tabular}

Fonte: MEC/Inep/DTDIE. Disponível em: <http://www.todospelaeducacao.org.br>. Acesso em: 12.08. 2015.

Na Tabela 7 verifica-se que a taxa de reprovação é maior nos anos iniciais do ensino fundamental de 1997 a 2012, com maior taxa entre 2005 a 2008, respectivamente $15,1 \%, 27,3 \%$ e $24,3 \%$. Em 2012, observa-se que o índice de reprovações teve uma diminuição significativa para $13,8 \%$ de reprovações, nos anos iniciais do ensino fundamental, e média de 12,2\% nos anos finais. Porém, há um percentual maior de abandono, nos anos finais do ensino fundamental, o que permite identificar, em face dos dados estatísticos, que houve dificuldades por parte dos estudantes quanto ao prosseguimento dos estudos.

Quanto às taxas de distorção idade-série da rede pública de ensino, identificam-se os dados de 1999 a 2012, a partir de fontes sobre estatística municipal, a seguir na Tabela 8:

Tabela 8 -Taxas de distorção idade-série - Rede Pública - 1999-2012

\begin{tabular}{llllllllllllll}
\hline & $\mathbf{1 9 9 9}$ & $\mathbf{2 0 0 0}$ & $\mathbf{2 0 0 1}$ & $\mathbf{2 0 0 2}$ & $\mathbf{2 0 0 3}$ & $\mathbf{2 0 0 4}$ & $\mathbf{2 0 0 5}$ & $\mathbf{2 0 0 7}$ & $\mathbf{2 0 0 8}$ & $\mathbf{2 0 0 9}$ & $\mathbf{2 0 1 0}$ & $\mathbf{2 0 1 1}$ & $\mathbf{2 0 1 2}$ \\
\hline AI & 80,1 & 73,9 & 63,8 & 63,4 & 57,5 & 54,8 & 54,5 & 37,1 & 24,7 & 29,9 & 30,7 & 29,9 & 30,9 \\
AF & 69,4 & 66,7 & 79,5 & 72,6 & 69,7 & 66 & 54,6 & 58,4 & 30,2 & 37,3 & 43,2 & 44,9 & 42,9 \\
\hline
\end{tabular}

Fonte: Elaborado pela autora com dados de MEC/Inep/Seduc/Idesp (2013) e site Todos pela Educação (2015).

As taxas de distorção idade-série da rede pública entre 1999 a 2012 são elevadas, principalmente entre os anos de 1999 a 2004, para os anos iniciais, e 1999 a 2007, para os anos finais do ensino fundamental. Nos demais anos, até 2012, percebe-se uma diminuição, em comparação ao período anterior, o que permite inferir uma realidade quanto ao quantitativo elevado de crianças, adolescentes e jovens acima da idade prevista para a série cursada.

A seguir, dados referentes aos níveis de ensino e modalidades da educação básica.

Modalidades de ensino e complementares

a) Educação de Jovens e Adultos - EJA 
A Educação de Jovens e Adultos (EJA) é uma modalidade de ensino voltada para o atendimento educacional de jovens e adultos. Está embasada no que determina a LDB, Lei 9.94.93/96, nos demais dispositivos que regem esta modalidade de ensino da educação básica, especificamente: o Parecer CNE/CEB/ 11/2000; Resolução CNE/CEB 01/2000; Resolução CNE/CEB 3, de 15/6/2010, que institui Diretrizes Operacionais para a Educação de Jovens e Adultos nos aspectos relativos à duração dos cursos e idade mínima para ingresso nos cursos de EJA; idade mínima e certificação nos exames de EJA; e Educação de Jovens e Adultos, desenvolvida por meio da Educação a Distância, o Plano Nacional de Educação (Lei 10.172/01), novo PNE (Lei 13.005, 25/06/2014), o PDE, dentre outros.

Tais dispositivos legais constituem um direito assegurado aos jovens e adultos que não puderam realizar seus estudos dentro da idade/série prevista, por alguma circunstância. Dentre as funções da EJA, os documentos dispõem sobre a ação reparadora, equalizadora e qualificadora desta educação para vida, escolarização e formação de jovens e adultos. A LDB trata da educação de jovens e adultos no Título V, capítulo II como modalidade da educação básica, superando sua dimensão de ensino supletivo, regulamentando sua oferta a todos aqueles que não tiveram acesso ou não concluíram o ensino fundamental.

\begin{abstract}
Artigo 37. A educação de jovens e adultos será destinada àqueles que não tiveram acesso ou continuidade de estudos no ensino fundamental e médio na idade própria. Parágrafo $1^{\circ}$ Os sistemas de ensino assegurarão gratuitamente aos jovens e aos adultos, que não puderam efetuar os estudos na idade regular, oportunidades educacionais apropriadas, consideradas as características do alunado, seus interesses, condições de vida e de trabalho, mediante cursos e exames. Parágrafo $2^{\circ} \mathrm{O}$ Poder Público viabilizará e estimulará o acesso e a permanência do trabalhador na escola, mediante ações integradas e complementares entre si. Artigo 38. Os sistemas de ensino manterão cursos e exames supletivos, que compreenderão a base nacional comum do currículo, habilitando ao prosseguimento de estudos em caráter regular. (BRASIL, 1996).
\end{abstract}

Ao consideramos os dados anteriormente apresentados sobre o baixo IDHMEducação de 0,478 do município, evidenciamos que Belterra infelizmente possuía, de acordo com o período identificado (1991/2000/2010), que abrange em parte os anos investigados (1997-2012), uma estatística educacional preocupante quanto à taxa de analfabetismo, em face da luta pelo direito à educação escolar no Brasil, em especial na região Amazônica.

Para fins de evidenciarmos esta realidade, relembramos que Belterra possuía taxa de analfabetismo com média de $12,4 \%$ de pessoas com 15 anos ou mais, em 2010, e de $5,8 \%$ de pessoas com 10 a 14 anos, a partir dos dados do Censo (IBGE, 2010). Detinha $16,9 \%$ de pessoas com ensino fundamental incompleto e analfabetos. Diante dos dados, a seguir apresentam-se informações quanto à oferta da Educação de Jovens E Adultos (EJA), nos anos de 1997-2012: 
Tabela 9 - Número de alunos matriculados na EJA - Intervalo entre gestões municipais - 1997-2012

\begin{tabular}{|c|c|c|c|c|c|}
\hline \multirow[b]{2}{*}{ Anos } & \multirow[b]{2}{*}{ Dependência/Nível } & \multicolumn{4}{|c|}{ Matrícula Inicial EJA (presencia e semipresencial/Supletivo) } \\
\hline & & Estadual & Municipal & Particular & Total \\
\hline \multirow[t]{2}{*}{1997} & E. Fundamental & NIF & NIF & - & \multirow[t]{2}{*}{-} \\
\hline & Ensino Médio & NIF & NIF & - & \\
\hline \multirow[t]{2}{*}{2000} & E. Fundamental & - & 103 & - & \multirow[t]{2}{*}{103} \\
\hline & Ensino Médio & - & - & - & \\
\hline \multirow[t]{2}{*}{2001} & E. Fundamental & - & 461 & - & \multirow[t]{2}{*}{550} \\
\hline & Ensino Médio & 89 & - & - & \\
\hline \multirow[t]{2}{*}{2004} & E. Fundamental & - & 93 & - & \multirow[t]{2}{*}{135} \\
\hline & Ensino Médio & 42 & - & - & \\
\hline \multirow[t]{2}{*}{2005} & E. Fundamental & - & 106 & & \multirow[t]{2}{*}{161} \\
\hline & Ensino Médio & 55 & - & & \\
\hline \multirow[t]{2}{*}{2008} & E. Fundamental & - & $456^{*}$ & - & \multirow[t]{2}{*}{534} \\
\hline & Ensino Médio & $78^{*}$ & - & - & \\
\hline \multirow[t]{2}{*}{2009} & E. Fundamental & - & $456^{*}$ & - & \multirow[t]{2}{*}{543} \\
\hline & Ensino Médio & $87 *$ & - & - & \\
\hline \multirow[t]{2}{*}{2012} & E. Fundamental & - & $461 *$ & - & \multirow[t]{2}{*}{550} \\
\hline & Ensino Médio & $89 *$ & - & - & \\
\hline
\end{tabular}

Fonte: Censo Escolar/Inep. Elaborado pela autora (2015).

* Incluídos alunos da EJA integrados à educação profissional, conforme Censo/Inep.

Na Tabela 9 destaca-se que a oferta de EJA em 1997 não tem dados informados no Censo da Educação Básica em 1997, tanto da rede pública estadual como municipal. Durante o período de 1997 a 2012, não há dados sobre a rede particular. Quanto ao atendimento da EJA na rede pública municipal, observa-se que a oferta da EJA (ensino fundamental) é realizada pela rede municipal e a oferta da EJA (ensino médio), pela rede estadual.

Quanto às taxas de matrículas da rede municipal, identifica-se que houve elevação no número de matrículas entre 2000 e 2001, de 103 para 461; porém, percebe-se que no ano seguinte (2001) houve uma grande redução no quantitativo de matrículas de alunos na EJA, média de 80\%, ao passo que, entre 2005 a 2012, observa-se um aumento nas matrículas na EJA.

\section{b) Educação Especial}

Quanto aos dados sobre educação especial, apresenta-se a Tabela 10:

Tabela 10 -Número de Matrículas na Educação Especial - Rede Municipal - 1997-2012 - Belterra

\begin{tabular}{|c|c|c|c|c|c|}
\hline \multirow[b]{3}{*}{ Anos } & \multicolumn{5}{|c|}{ Matrículas } \\
\hline & \multicolumn{5}{|c|}{ Educação Especial (Alunos de Esc. Especiais, Classes Especiais e Incluídos) } \\
\hline & Ed. Infantil & E. Fundamental & EJA Fund $^{1,2}$ & $\begin{array}{l}\text { Educação Especial } \\
\text { (Incluídos) * }\end{array}$ & $\begin{array}{c}\text { Educação Especial } \\
\text { Total** }\end{array}$ \\
\hline 1997 & - & - & - & - & - \\
\hline 1998 & - & - & - & - & - \\
\hline 1999 & - & 4 & - & - & 4 \\
\hline 2000 & 1 & 9 & - & - & 10 \\
\hline 2001 & 1 & 10 & 1 & - & 12 \\
\hline $2002 * *$ & & & & & 5 \\
\hline $2003 * *$ & & & & & 8 \\
\hline 2004 & - & 7 & - & 13 & 20 \\
\hline 2005 & - & 6 & - & 25 & 31 \\
\hline
\end{tabular}




\begin{tabular}{l|llllc}
\hline 2006 & - & 7 & - & 21 & 28 \\
2007 & 1 & - & - & - & 1 \\
2008 & 1 & - & - & - & 1 \\
2009 & 4 & 35 & 2 & - & 35 \\
2010 & - & 27 & 3 & - & - \\
2011 & 1 & 30 & 4 & 1 & - \\
2012 & 1 & 8 & C
\end{tabular}

Fonte: Censo Escolar/Inep, site Observatório do PNE.

1- Inclui os alunos do Ensino Médio Integrado e Ensino Médio Normal/ Magistério.

2- Inclui os alunos da Educação de Jovens e Adultos Integrada à Educação Profissional.

* De acordo com os resultados do Censo Escolar de 2004 a 2006, identificou-se apenas a matrícula

denominada de educação especial (incluídos) na base de dados do site do Inep, sem detalhamento.

** De acordo com os resultados do Censo Escolar de 2002 e 2003, identificou-se apenas a matrícula total na base de dados do site do Inep.

Na Tabela 10 nota-se que há uma elevação no quantitativo de matrículas entre os anos de 1999 a 2001, de 2004 a 2006, e de 2009 a 2011, bem como expansão do atendimento escolar na educação infantil, ensino fundamental e EJA (ensino fundamental), e com alunos matriculados, considerados da educação especial. Identifica-se, na Tabela 10, que a matrícula teve início no censo escolar pela rede municipal em 1999, com informação declarada de 4 matrículas no ensino fundamental; em 2000 houve número de matrícula na educação infantil (pré-escola), e em 2001, matrícula de 1 aluno na EJA (ensino fundamental). Entretanto, observa-se que nos períodos 2002-2003, 2007-2008 e 2012 há uma redução no número de matrículas, assim informadas no Censo Escolar/Inep, respectivamente, de pouco mais de 50\%, em 2002, uma brusca redução em 2007 e 2008 , retrocedendo para ínfimo número de 01 matrícula.

A Constituição Federal de 1988 estabelece o direito de as pessoas com necessidades especiais receberem educação, preferencialmente na rede regular de ensino (art. 208, III). A LDB determina que os sistemas de ensino devem assegurar aos educandos com necessidades especiais:

[...] currículos, métodos, técnicas, recursos educativos e organização específicos, para atender às suas necessidades; II. terminalidade específica para aqueles que não puderem atingir o nível exigido para a conclusão do ensino fundamental, em virtude de suas deficiências, e aceleração para concluir em menor tempo o programa escolar para os superdotados; III. professores com especialização adequada em nível médio ou superior, para atendimento especializado, bem como professores do ensino regular capacitados para a integração desses educandos nas classes comuns; IV. educação especial para o trabalho, visando à sua efetiva integração na vida em sociedade, inclusive condições adequadas para os que não revelarem capacidade de inserção no trabalho competitivo, mediante articulação com os órgão oficiais afins, bem como para aqueles que apresentam uma habilidade superior nas áreas artística, intelectual ou psicomotora; V. acesso igualitário aos benefícios dos programas sociais suplementares disponíveis para o respectivo nível do ensino regular. (BRASIL, 1996, art. 59).

Em 2006, a Semed cria a Coordenação de Educação Especial, para o acompanhamento pedagógico junto às escolas da rede, havendo, porém, apenas $1 \mathrm{um}$ servidor com formação pedagógica, conforme o Relatório da Semed (2006). Destaca-se que a educação especial é uma modalidade de ensino destinada a educandos com necessidades educativas especiais no campo da aprendizagem, originadas quer de 
deficiência física, sensorial, mental ou múltipla, quer de características como altas habilidades, superdotação ou talentos.

\section{c) Modalidade Complementar: Educação Escolar Indígena}

A partir da CF 1988 e da LDB, seguem-se documentos importantes da luta do processo de reconhecimento e identidade indígena, tanto nacionais como internacionais, que versam sobre $\mathrm{o}$ direito à educação escolar pública indígena. Para fins de exemplificação, citam-se as Convenções 107 e 169 da Organização Internacional do Trabalho (OIT) e a Declaração sobre os Direitos dos Povos Indígenas da Organização dos Estados Americanos (OEA). Segundo Grupioni (2001, p.21), nos artigos 78 e 79 do Ato das Disposições Gerais e Transitórias da Constituição de 1988, preconiza-se como dever do Estado o oferecimento de uma educação escolar bilíngue e intercultural,

[...] que fortaleça as práticas socioculturais e a língua materna de cada comunidade indígena e proporcione a oportunidade de recuperar suas memórias históricas e reafirmar suas identidades, dando-lhes, também, acesso aos conhecimentos técnico científicos da sociedade nacional. Para que isso possa ocorrer, a LDB determina a articulação dos sistemas de ensino para a elaboração de programas integrados de ensino e pesquisa, que contem com a participação das comunidades indígenas em sua formulação e tenham como objetivo desenvolver currículos específicos, neles incluindo os conteúdos culturais correspondentes às respectivas comunidades. A LDB ainda prevê a formação de pessoal especializado para atuar nessa área e a elaboração e publicação de materiais didáticos específicos e diferenciados.

Em relação à educação escolar indígena, em Belterra, conforme Relatório da Semed (2012), as escolas indígenas, assim reconhecidas pela administração local, pertencem às comunidades de Marituba, Takuara e Bragança, localizadas na região do Tapajós. Em 2005 foi criada na Semed a Coordenação de Educação Escolar Indígena, sob responsabilidade de 1 servidor; porém por necessidade de orientações e informações, não eram declaradas no censo escolar as matrículas de alunos indígenas, conforme depoimento coletado da entrevista com secretários municipais, parte integrante de fonte desta pesquisa.

Quanto à infraestrutura das escolas, conforme Colares (2013), ainda necessitava de melhores condições de ensino e infraestrutura, assim como os demais estabelecimentos escolares da rede municipal, em sua maioria, da área rural. A partir desta consideração, ressalta-se que as escolas necessitavam de adequação e elaboração de projetos políticopedagógicos, voltados para educação e cultura indígenas, assim previstos nas orientações legais. Para fins de ilustração, apresentam-se imagens de um dos estabelecimentos para atendimento escolar indígena, na Figura 2. 
Figura 2 -Fotos do estabelecimento de atendimento escolar indígena de Marituba

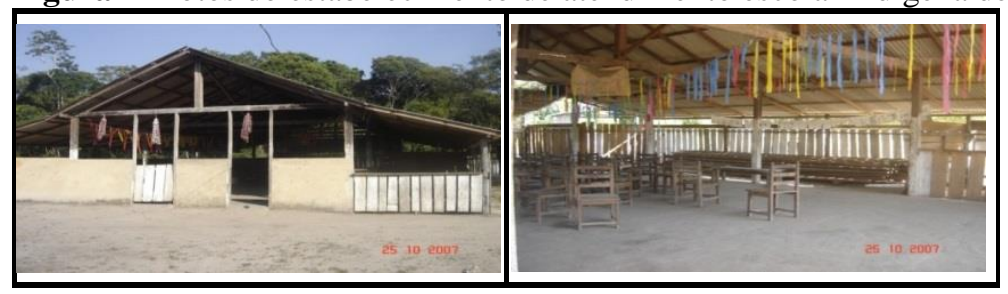

Fonte: Imagens do arquivo pessoal da autora (2007).

A seguir, apresentam-se dados em relação às matrículas da educação infantil totais de 2007 a 2012, da educação escolar indígena, encontrados no Censo Escolar/Inep.

Tabela 11 - Matrículas da Educação Infantil e Ensino Fundamental - Educação Escolar Indígena - Rede Pública Municipal - 1997-2012

\begin{tabular}{ccc}
\hline Ano & Educação Infantil & Ensino Fundamental \\
\hline $\mathbf{1 9 9 7 - 2 0 0 8}$ & 0 & 0 \\
$\mathbf{2 0 0 9}$ & 15 & 98 \\
$\mathbf{2 0 1 0}$ & 16 & 100 \\
$\mathbf{2 0 1 1}$ & 8 & 98 \\
$\mathbf{2 0 1 2}$ & 12 & 101 \\
\hline
\end{tabular}

Fonte: MEC/Inep/Deed/Censo Escolar / Preparação: Todos Pela Educação.

$\mathrm{Na}$ Tabela 11 percebe-se que as matrículas de educação escolar indígena foram informadas no Censo Escolar/Inep a partir de 2009, com 15 alunos matriculados na educação infantil e 98 alunos matriculados no ensino fundamental. Destaca-se que houve uma redução na matrícula da educação infantil em 2011, com aumento de 4 matrículas no ano seguinte (2012). Enquanto a matrícula no ensino fundamental entre 2009-2012 era de 98 a 101 alunos matriculados, no mesmo período, as matrículas no Brasil totalizavam, respectivamente, número de 164.727 (2009) e número de 167.338 (2012), segundo MEC/Inep/Deed/Censo Escolar e Relatório do site Todos Pela Educação.

Ao prosseguir, ainda sobre informações da educação escolar indígena em Belterra, segundo Rodrigues (2013, p. 176), destaca-se que na comunidade de Takuara

[...] em mil novecentos e noventa e oito iniciou-se um movimento pela garantia do direito de implantação da escola indígena. Em dois mil e três foi implantada uma escola fundamental com turmas de primeira a quarta séries. Em outubro de 2011 foi festivamente comemorada a implantação do ensino médio nesta escola, contemplando doze alunos agrupados em uma turma do 'primeiro colegial'.

Rodrigues (2013) evidencia que no ano de 2011 houve implantação de ensino médio na comunidade, atendendo à demanda por prosseguimento de estudos por parte dos alunos. E em 2008 iniciou-se a oferta de turmas de magistério indígena pela $5^{\mathrm{a}}$ URE/Seduc em parceria com Semed/Belterra.

\section{d) Modalidade Complementar: Educação do Campo}

A educação do campo, segundo o Decreto $\mathrm{n}^{\circ}$ 7.352, de 4 de novembro de 2010, que dispõe sobre a política de educação do campo, e o Programa Nacional de Educação na Reforma Agrária - Pronera, é compreendida como direito à educação para as populações que moram no campo, a ser assegurado pela União, estados e municípios, no sentido de 
garantir e ampliar o acesso, permanência e sucesso escolar, assim determinado no art. $1^{\circ}$ do Decreto.

\begin{abstract}
Art. $1^{0}$ A política de educação do campo destina-se à ampliação e qualificação da oferta de educação básica e superior às populações do campo, e será desenvolvida pela União em regime de colaboração com os Estados, o Distrito Federal e os Municípios, de acordo com as diretrizes e metas estabelecidas no Plano Nacional de Educação e o disposto neste Decreto (BRASIL, 2010b).
\end{abstract}

Deste modo, cabe à União, em regime de colaboração com demais entes federados, de acordo com o Art. $3^{-0}$ do Decreto 7.352, criar e implementar mecanismos que "garantam a manutenção e o desenvolvimento da educação do campo nas políticas públicas educacionais, com o objetivo de superar as defasagens históricas de acesso à educação escolar pelas populações do campo" (BRASIL, 2010b). Diante da legislação educacional, interessa-nos aqui "olhar para realidade educacional em Belterra", considerando o contexto heterogêneo da Amazônia Paraense, bem como a particularidade municipal de expressiva característica rural.

Deste modo, compreendemos a importância de apresentar dados sobre a educação do campo em Belterra, dentro da limitação de estudo, nesta seção quanto ao panorama sobre a educação escolar. Por isso, destaca-se o número de matrículas de educação infantil e ensino fundamental, a partir dos dados que conseguimos identificar, para fins desta pesquisa, assim demonstrados na Tabela 12. Dentre os anos de 1997 a 2012, obtivemos dados estimados, de número de escolas:

Tabela 12 - Matrículas da Educação Infantil e Ensino Fundamental - Educação do Campo - Rede Pública Municipal - 1997-2012

\begin{tabular}{ccc}
\hline Ano & Educação Infantil & Ensino Fundamental \\
\hline $\mathbf{1 9 9 7 - 2 0 0 6}$ & NIF & NIF \\
$\mathbf{2 0 0 7}$ & 157 & 2.686 \\
$\mathbf{2 0 0 8}$ & 198 & 2.612 \\
$\mathbf{2 0 0 9}$ & 331 & 2.468 \\
$\mathbf{2 0 1 0}$ & 411 & 2.511 \\
$\mathbf{2 0 1 1}$ & 325 & 2.474 \\
$\mathbf{2 0 1 2}$ & 366 & 2.389 \\
\hline \multicolumn{3}{c}{ Fonte: MEC/Inep/Deed/Censo Escolar (2015). Preparação: Todos Pela Educação. } \\
\end{tabular}

Na Tabela 12, identifica-se que entre 2007 a 2012 houve uma elevação do número de matrículas na educação infantil nas escolas do campo, com elevação maior em 2010 (411). Entretanto, observa-se uma leve diminuição no quantitativo de matrículas no ensino fundamental, com quantitativo em 2007 de 2.686 alunos matriculados, ao passo que em 2012 foi de 2.389 matrículas, menos 297 vagas escolares.

Quanto ao demonstrativo comparativo de número de matrículas do ensino fundamental, da área urbana e rural, temos: 
Quadro 01 - Número de matrículas - Ensino Fundamental - Demonstrativo 1997-2012* - Área Rural

\begin{tabular}{|c|c|c|c|c|c|c|c|c|c|c|}
\hline \multirow{2}{*}{\multicolumn{2}{|c|}{$\begin{array}{c}\text { Ano/ Dependência } \\
\text { Administrativa/ } \\
\text { Área }\end{array}$}} & \multicolumn{9}{|c|}{ Número de matrículas - Matrícula Final } \\
\hline & & \multicolumn{9}{|c|}{ Nível de Ensino - Ensino Fundamental } \\
\hline \multicolumn{2}{|c|}{$\begin{array}{c}\text { Ensino } \\
\text { Fundamental }\end{array}$} & $1^{\circ}$ Ano & $2^{\circ}$ Ano & $3^{\circ}$ Ano & $4^{\circ}$ Ano & $5^{\circ}$ Ano & $6^{\circ}$ Ano & $7^{\circ}$ Ano & $8^{\circ}$ Ano & $9^{\circ}$ Ano \\
\hline $\begin{array}{c}1997 \\
- \\
2009\end{array}$ & $\begin{array}{l}\text { Municipal } \\
\text { Rural/ } \\
\text { Urbana }\end{array}$ & - & - & - & - & - & - & - & - & - \\
\hline \multirow{3}{*}{2010} & Municipal & 358 & 528 & 551 & 561 & 500 & 572 & 428 & 316 & 220 \\
\hline & Rural & 245 & 334 & 349 & 372 & 312 & 344 & 238 & 189 & 128 \\
\hline & Urbana & 113 & 194 & 202 & 189 & 188 & 228 & 190 & 127 & 92 \\
\hline \multirow{3}{*}{2011} & Municipal & 417 & 502 & 504 & 537 & 468 & 540 & 464 & 319 & 269 \\
\hline & Rural & 273 & 325 & 322 & 338 & 295 & 321 & 254 & 187 & 159 \\
\hline & Urbana & 144 & 177 & 182 & 199 & 173 & 219 & 210 & 132 & 110 \\
\hline \multirow[b]{3}{*}{2012} & Municipal & 347 & 564 & 494 & 466 & 487 & 489 & 405 & 368 & 258 \\
\hline & Rural & 229 & 351 & 311 & 306 & 297 & 304 & 233 & 213 & 145 \\
\hline & Urbana & 118 & 213 & 183 & 160 & 190 & 185 & 172 & 155 & 113 \\
\hline
\end{tabular}

Fonte: Relatório Sistema Gestor da Semed (2010, 2011, 2012).

*Apresentação dos dados que foram possíveis de serem identificados, dentro da limitação desta pesquisa. Apesar de não compreender todo o período investigado, consideramos importante destacar estes dados sobre a educação da área rural.

A partir dos dados obtidos junto à Semed, no Relatório do Sistema Gestor de Dados Escolares (2010/2011/2012), conseguimos, para fins deste trabalho, realizar um demonstrativo de informações sobre matrícula por nível/turma, comparativo da área urbana e rural. Deste modo, a partir dos dados apresentados no Quadro 1, identifica-se que o número de matrículas no ensino fundamental, na área rural, é quantitativamente maior do que a matrícula da área urbana, entre 2010 a 2012, e que há uma diminuição de matrículas entre os anos iniciais e finais, "a entrada e a saída" no ensino fundamental.

No ano de 2012 o número de matrículas (final) nos anos finais $\left(6^{\circ}\right.$ ao $9^{\circ}$ ano) do ensino fundamental foi de apenas 1.520 , menor se comparado com número de matrículas dos anos iniciais ( $1^{\circ}$ a $5^{\circ}$ ano), diferença de 838 matrículas. Ao observamos a taxa de rendimento escolar na área rural, no mesmo período, entre 2010/2012, temos cerca de $13,90 \%$ de reprovações nos anos iniciais, e taxa maior de abandono nos anos finais, refletindo numa redução do número de matrículas. Quanto à distorção idade-série nos anos iniciais $\left(1^{\circ}\right.$ a $5^{\circ}$ ano) do ensino fundamental a rede de ensino municipal, da área rural, em 2012, teve $33 \%$, ou seja, do total de 100 alunos, aproximadamente 33 estavam com atraso escolar de 2 anos ou mais, segundo o Inep (2013) e o PNUD/Atlas (2013).

Ao prosseguir sobre a educação do campo em Belterra, identificamos que a organização do ensino em Belterra, nos primeiros anos de emancipação, consistia de aproximadamente $99 \%$ a $100 \%$ de escolas com turmas multisseriadas na rede pública municipal, segundo dados dos depoimentos de (ex-) servidores da Semed ${ }^{6}$. Em 2007, segundo Meadts (2007), cerca de $96 \%$ das escolas ainda possuíam a organização de turmas com ensino multisseriado, e em 2012, a rede tinha em média $80 \%$, segundo relatório do Sistema Gestor da Semed (2012). Quanto aos espaços escolares destinados à oferta do ensino, havia espaços escolares apropriados e/ou adaptados, com ou sem divisões de espaços para banheiro, cozinha, secretaria, diretoria ou outros, prédios com média de 1 a 5 salas de aula, da maioria da rede.

Ao se tratar de espaços escolares, compreendem-se os estabelecimentos escolares, por vezes adaptados, como igrejas, barracões comunitários, casas alugadas, sedes esportivas, alguns construídos de madeira, alvenaria, palha, dentre outros espaços.Tal situação permite dimensionar, a partir do número significativo da existência das classes 
multisseriadas/multianos e da infraestrutura das escolas, os desafios que caracterizam o ensino, a formação, atuação de professores, de políticas dentre outros.

Deste modo, ao tratarmos da educação do campo em Belterra, destacamos o contexto mais amplo do estado do Pará, apresentado no $2^{\circ}$ Caderno sobre a Educação Básica do Estado (PARÁ, 2008) do Grupo de Estudos e Pesquisas sobre Educação Rural na Amazônia (Geperuaz), quando Hage (2008) ressalta que 71,7\% das escolas que oferecem o ensino fundamental de $1^{\mathrm{a}}$ a $4^{\mathrm{a}}$ série são exclusivamente multisseriadas e atendem a 394.948 alunos (46,6\%) no Pará (MEC/Inep, 2011), com total de 76.229 escolas do campo; 71,37\% (54.405) têm salas com estudantes de diversas séries, que somam $22 \%$ (1.384.654) das matrículas totais do campo (6.293.885), segundo o Censo Escolar Inep 2011.

Quanto ao contexto nacional, tem-se a presença de cerca $45 \%$ de classes multisseriadas no Brasil, segundo o Inep (2011). Ou seja, turmas de $1^{\mathrm{a}}$ a $4^{\mathrm{a}}$ série $\left(1^{\mathrm{o}}\right.$ ano ao $9^{\circ}$ ) do ensino fundamental agrupadas em único espaço escolar e com professores unidocentes, que possuem a tarefa de lecionar, concomitantemente, 1 ano letivo para mais de uma série/ano, com a mesma carga horária prevista em lei. Confrontando-se com concepções do modelo de seriação, tem-se um dilema face ao planejamento, organização didático-pedagógica, avaliação e currículo.

E, em Belterra, a partir de depoimentos de pessoas que trabalharam na Semed, em 1997 a rede municipal detinha uma estimativa de $100 \%$ de presença de turmas multisseriadas; no ano de 2006, segundo Meadtes (2007), a rede municipal tinha cerca de 96\% de classes multisseriadas; e em 2012 ainda teve aproximadamente $80 \%$ de escolas com presença de turmas de multianos, o que permite inferir os desafios para a gestão da Secretaria de Educação diante desta realidade da educação municipal.

Tais desafios são apontados por pesquisas sobre educação escolar no Brasil, como Hage (2008), Caldart (2009) e Ximenes-Rocha (2012), e revelam a problemática da educação das classes multisseriadas/multianos, dos diagnósticos e cenários dessas escolas, em sua maioria nas regiões Norte e Nordeste, com indicadores de baixo Índice de Desempenho da Educação Básica (Ideb), baixa/falta de qualificação docente, precárias condições de trabalho e infraestrutura das escolas, transporte escolar, necessidade de políticas públicas educacionais para educação no campo, dentre outros.

Apesar destes aspectos da educação escolar de municípios do Pará, Amazônia Brasileira, por vezes caracterizada pela falta, pelo silenciamento de políticas públicas e educacionais, as classes multisseriadas/multianos sobrevivem e resistem há mais de cem anos na história da educação escolar no Brasil, conforme Cardoso e Jacomeli (2010). E, neste cenário, os professores que atuam nestas classes cumprem papel social e político, também, pela educação dos sujeitos que moram no campo. Entretanto, muitos não possuem formação adequada para docência; nesta realidade específica, por vezes não possuem formação inicial ou são carentes de políticas de formação continuada voltadas para educação do campo.

De acordo com Ximenes-Rocha (2012), muitos destes professores são leigos, porém assumem a importância do ato de aprender a ensinar, diante da responsabilidade pela educação escolar de muitas crianças, adolescentes, jovens e adultos. Estes professores das escolas do campo tornam-se agentes de mudança, no sentido de garantir a oferta da educação pública à população, mesmo com as adversidades e assimetrias geográficas e socioeconômicas da região Amazônica, porém necessitam de políticas educacionais que garantam condições necessárias para o exercício profissional, bem como para a permanência e sucesso escolar dos estudantes. 


\section{e) Educação Ambiental (Temática Transversal e Interdisciplinar)}

Apesar de não ser uma modalidade de ensino, destacamos para fins deste trabalho, a temática da educação ambiental, por sua relevância e peculiaridade nas ações da Semed/Belterra. No contexto macro, enfatiza-se que a Política Nacional da Educação Ambiental foi instituída em 27 de abril de 1999, sendo sancionada pela Lei ${ }^{\circ}$ 9.795, em que se garante que a educação ambiental possa a ser uma prática nacional em todas as escolas.

A temática está inserida também nos Parâmetros Curriculares Nacionais (1997), como tema transversal e interdisciplinar, com orientações metodológicas a serem promovidas e desenvolvidas nas escolas para formação de professores, além de elaboração e desenvolvimento de projetos e programas que tenham por objetivo construir um processo permanente de educação ambiental em âmbito escolar e comunitário.

Em relação à educação ambiental na rede pública de ensino, apresentam-se alguns fatos, conforme o Quadro 2:

Quadro 2 - Registro de fatos e ações de Educação Ambiental entre 1997- 2012

\begin{tabular}{|c||l|l|}
\hline \hline Período & \multicolumn{1}{|c|}{ Fatos e Ações } \\
\hline 1997-2000 & $\begin{array}{l}\text { Assinatura de Acordo de Cooperação Técnica Ibama/ProManejo/Prefeitura de Belterra } \\
\text { Início do planejamento para a construção do Programa de Educação Ambiental da Rede } \\
\text { Municipal de Ensino de Belterra }\end{array}$ \\
\hline 2001-2004 & $\begin{array}{l}\text { Vigência do Acordo Ibama/ProManejo/Prefeitura de Belterra } \\
\text { Produção e difusão de materiais pedagógicos e Ações no Entorno da Flona e Programas com } \\
\text { Comunidades } \\
\text { Criação do Centro de Referência em Educação Ambiental - Cerea }\end{array}$ \\
\hline $2005-2008$ & $\begin{array}{l}\text { Revitalização do Cerea; Criação de Coordenação de Educação Ambiental na Semed } \\
\text { Realização de Agenda 21 nas Escolas eI Conferência Infantojuvenil pelo Meio Ambiente } \\
\text { (Municipal e nas escolas); Plano de Ação sobre discussão sobre EA e desenvolvimentos de } \\
\text { projetos e realização de parcerias; Aprovação do Plano Diretor }\end{array}$ \\
\hline $2009-2012$ & $\begin{array}{l}\text { II Conferência Infantojuvenil pelo Meio Ambiente (Municipal e nas Escolas) } \\
\text { Plano de Ação sobre discussão sobre EA no PPP das escolas municipais e desenvolvimentos de } \\
\text { projetos e realização de parcerias; Ações voltadas para EA decorrentes da Base Física do } \\
\text { Instituto Butantan }\end{array}$ \\
\hline
\end{tabular}

Fonte: Relatório do Plano de Manejo Florestal: Plano de EA/Flona (2001). Relatório de Revitalização do

Cerea (2004). Plano de Trabalho da Coordenação de EA/Semed (2008). Depoimento Departamento Pedagógico Semed (2012).

Os dados apresentados no Quadro 2 referem-se a uma amostra de fatos e/ou ações sobre EA nas escolas da rede pública de Belterra. Diante dos documentos referenciais sobre educação ambiental e do demonstrativo de fatos/ações no Quadro 2, destaca-se que no município de Belterra a temática ambiental tem caracterizado uma de suas "marcas" nas mais diversas áreas, entre elas a área educacional. Ao considerar sua localização dentro do contexto amazônico, permite-se evidenciar ao município condições propícias de pesquisas científicas e acadêmicas (ensino e extensão), desenvolvimento de projetos e programas voltados para temática de educação ambiental.

\section{Indicadores educacionais do município}

Ao considerarmos os dados apresentados anteriormente, sobre rede física de escolas, número de docentes, elevação e distribuição de matrículas e modalidades de ensino, taxas de rendimento escolar, distorção idade-série/ano, em Belterra, evidenciamos 
dados sobre indicadores educacionais do município, a partir dos dados identificados, em relação ao IDHM Educação, a seguir na Tabela 13.

Tabela 133- Índice de Desenvolvimento Humano Municipal - Educação - Belterra - 1991/2000/2010*

\begin{tabular}{crrr}
\hline & $\mathbf{1 9 9 1}$ & $\mathbf{2 0 0 0}$ & $\mathbf{2 0 1 0}$ \\
\hline IDHM Educação & 0,112 & 0,210 & 0,478 \\
\% de crianças de 0 a 5 anos fora da escola & - & 91,13 & 68,00 \\
\% de crianças de 6 a 14 fora da escola & 29,89 & 12,91 & 3,44 \\
\% de pessoas de 15 a 24 anos que não estudam, não trabalham e são & - & 34,96 & 23,21 \\
vulneráveis, na população dessa faixa & & \\
\% de 18 anos ou mais com ensino fundamental completo & 13,13 & 19,50 & 36,87 \\
\% de 5 a 6 anos frequentando a escola & 18,94 & 39,68 & 80,34 \\
\% de 11 a 13 anos frequentando os anos finais do ensino fundamental & 13,67 & 27,02 & 74,98 \\
\% de 15 a 17 anos com ensino fundamental completo & 6,08 & 13,57 & 36,30 \\
\% de 18 a 20 anos com ensino médio completo & 2,49 & 6,85 & 26,14 \\
\% Pessoas com Fundamental incompleto e analfabeto & 34,05 & 25,30 & 16,19 \\
\%Pessoas com Fundamental incompleto e alfabetizado & 55,03 & 59,65 & 52,29 \\
\%Pessoas com Fundamental completo e médio incompleto & 4,69 & 8,68 & 11,31 \\
\%Pessoas com Médio completo e ensino superior incompleto & 5,15 & 6,17 & 17,17 \\
\%Pessoas com Ensino superior completo & 1,08 & 0,20 & 3,04 \\
\hline
\end{tabular}

Fonte: IBGE (2010). Atlas/PNUD (2013). Disponível em: <http://www.qedu.org.br/brasil/ideb/ . Acesso em: 12.04.2015.

* Os dados apresentados correspondem aos anos em que foram informados nas fontes citadas.

O município apresentou IDHM, com a variação entre 1991 a 2010, respectivamente, de 0,112 e 0,478, sendo IDHM-Educação de nível baixo, segundo o IBGE (2015). Destaca-se que o município teve uma diminuição relativa na proporção de crianças de 0 a 5 anos fora da escola, de $90,13 \%$ de 1991, para $68 \%$ duas décadas depois, em 2010. Houve uma considerável diminuição no percentual de crianças de 6 a 14 anos fora da escola e, consequentemente, aumento da faixa etária de 5 a 6 anos, de 11 a 13 anos frequentando a escola, em especial o ensino fundamental. Porém, há um percentual ainda de jovens de 18 anos ou mais completando seus estudos no nível fundamental, de 13,3\% em 1991 e $36,87 \%$, em 2010. Contudo, percebe-se uma melhora no percentual de jovens entre 18 a 20 anos completando os estudos em nível médio; anteriormente, na década de 2000 a 2010, a média teve elevação de pouco mais de 4\% (1991 a 2000).

Segundo o relatório Atlas 2013/PNUD (2015), considerando a Tabela 13, observase que entre 1991 a 2010 o percentual de pessoas com ensino fundamental incompleto e analfabetas decresceu de 34,05\% (1991) para 16,19\% em 2010. No censo de 2010, conforme dado mais recente divulgado no site do IBGE (2015), identifica-se o percentual de $12,4 \%$ (15 anos ou mais), 5,8\% de 10 a 14 anos, estatística preocupante da realidade e desafios a serem enfrentados na educação do município, quanto ao direito constitucional.

O percentual de faixa etária de escolarização baixa é de apenas $26,14 \%$ de jovens entre 18 a 20 anos com ensino médio completo. Diante destes dados, faz-se necessário pensar os desafios para o campo educacional. De acordo com Perez (2010), pensar a agenda de formulação, implementação e avaliação de políticas públicas educacionais a serem conduzidas pelo Estado Brasileiro, pelo município como Ente Federado, perante a sua população.

Nestes termos, entendemos que as políticas educacionais tornam-se possibilidades de melhoria na educação para minimizar as desigualdades sociais existentes, diante do processo de globalização, mundialização vigente na ordem político-econômica mundial, assim analisadas também por Azevedo (2001) e Mészaros (2008). 
Na Tabela 13, destaca-se que o percentual de pessoas com ensino fundamental incompleto e analfabetos no ano de 2010 era de $16,19 \%$, diminuição de pouco mais de $50 \%$ da média de duas décadas, considerando-se que em 1991 era de 34,05\%. Porém, os dados refletem uma percepção de grande parcela de adolescentes, jovens e adultos considerados não alfabetizados. Segundo Prado (2007), residem nesta estatística, infelizmente, anos de história da sociedade brasileira, de políticas públicas não efetivas, com exceção de ações governamentais da década de 1960, e que, atualmente, existem ações em âmbito municipal, que porém merecem a atenção das esferas de governo estadual e federal.

Dentre os dados apresentados - sem desconsiderar a periodização da pesquisa, mas o que foi possível identificar para fins deste trabalho - que durante as duas décadas as taxas de frequência no ensino médio são baixas e o percentual de pessoas que conseguem concluir o ensino superior é menor; e, ainda, a média é de apenas 3,04\% em 2010, abaixo da média de 11,27\% nacional, bem como abaixo da do próprio estado do Pará, que é de apenas 6,21\%, o que reflete o ainda pouco acesso ao ensino superior por parte da população, segundo relatório da Fapespa (2015).

Em termos gerais, os dados permitem identificar a problemática vivenciada por parte da população, tanto quanto ao acesso à educação escolar, com a diminuição de percentuais de analfabetismo, como a busca por melhoria na distribuição de renda, observados no índice de 0,548, segundo dados do PNUD/Ipea/FJP/Atlas 2013, advindos do Programa das Nações Unidas para o Desenvolvimento (PNDU) e do relatório da ONU.

Quanto ao analfabetismo, Saviani (2006) avalia ser ainda uma tarefa do Brasil cumprir a missão do século XIX, quanto à universalização e democratização da educação escolar, com a eliminação do analfabetismo, o que ainda é perceptível nos números apresentados da realidade educacional de Belterra. Se voltarmos um pouco na história, Bittar (2012) apresenta que a defasagem educacional com que o Brasil ingressou no século XX, em 1900, era de 65,3\% analfabetos (mais de 15 anos de idade); em 1970, com uma população de 94.501 .554 habitantes, o analfabetismo era de 33,1\%; e segundo Romanelli (1986, p. 64), “em 1888 tínhamos 250.000 alunos para uma população de 14 milhões de habitantes".

Ao considerar o contexto amazônico, segundo Loureiro (2004), esta situação se refletia nos dados estatísticos no ano de 1940 do Instituto Brasileiro de Geografia e Estatística (IBGE), segundo os quais apenas 33\% da população total da região sabiam ler e escrever, sendo que, acima dos 18 anos, este índice decrescia para 10\%, num quadro mais crítico ainda. Diante desta situação da defasagem educacional, abordada por Bittar (2012), Loureiro (2004) e Romanelli (1986), destaca-se que a taxa de analfabetismo (de 15 anos ou mais) do Brasil é de $10 \%$ e a do Pará é 11,74\%, segundo o PNUD/Ipea/Atlas (2013); porém, verifica-se que, no ano de 2011, a taxa de analfabetismo foi estimada em 8,6\%, o que correspondeu ao contingente de 12,9 milhões de analfabetos, segundo Araújo (2013).

Permite-se, então, refletir sobre a necessidade de conquista da cidadania plena de pessoas ainda analfabetas (16,9\% em Belterra), ainda à margem do direito constitucional. Contudo, Prado (2007, p.31) destaca que faz-se necessário um novo "olhar" sobre os conceitos de analfabetismo, alfabetização e analfabetismo funcional, alfabetizado $e$ analfabetizado funcional, superando, no caso da alfabetização, o conceito de "saber ler, escrever um bilhete simples", critério adotado durante muitos anos pelo IBGE e criticado por vários autores, o qual precisa ser repensado, problematizado.

Em face dos dados apresentados neste artigo, ressalta-se que, ao considerar a educação como política pública, busca-se em Saviani (2000), por exemplo, perceber que na modernidade a escola se tornou referência da transmissão do saber, pela instrução das 
classes trabalhadoras, constituída dentro de uma base de sociedade capitalista, tendo na contradição entre as classes a definição e marcas que configuram a função da escola, quando generalizada, na forma da educação escolar básica.

Neste cerne, ao considerar a tardia constituição legal da educação como direito público social, faz-se necessário pensar uma educação escolar pública para a população, principalmente para a classe trabalhadora, de forma a garantir o acesso, a permanência e o sucesso escolar. Disto, porém, resulta um dilema a ser enfrentado pelas esferas de governo, pela União, estados e municípios, a exemplo de Belterra, a partir de políticas educacionais numa perspectiva mais democrática e descentralizadora.

Porém, ao considerarmos que a taxa de analfabetismo de $12 \%$ da sua população em 2010, além de outras estatísticas de indicadores educacionais reveladores da exclusão do direito à educação e de aprendizagem, como evasão e reprovação, podemos inferir que ainda o Estado Brasileiro, em especial, para a região amazônica, precisa implementar políticas educacionais que possam enfrentar os problemas de desigualdades, advindas de um processo histórico excludente do direito à educação. E, que apenas os Municípios isoladamente, não podem assumir unicamente.

A despeito das ações da Semed, de suas gestões, e aos problemas educacionais presentes historicamente no Município, concordamos com Camargo (2006, p.5) ao destacar que

\begin{abstract}
Além desses problemas, os gestores municipais da Educação lidam com outros fenômenos que causam impacto no desenvolvimento de seu trabalho: os elevados índices de repetência e evasão escolar, a baixa autoestima dos professores — os quais demandam mais estímulo e oportunidade para exercitar sua criatividade e serem reconhecidos - , a falta de acesso das comunidades escolares a recursos pedagógicos simples como livros e jornais, o baixo poder aquisitivo das famílias, a baixa [...]distância e localização das escolas (dificultando o acesso), o período das chuvas (que alaga boa parte do território e força grande número de famílias a viver sobre as águas ou a se mudar para as áreas secas, só retornando para suas casas originais quando os rios secam). A despeito das dificuldades, vários atores sociais continuam determinados a enfrentar os desafios locais, buscando garantir a eficiência do ensino. Cada vez mais, a sociedade local, as instituições governamentais e as não governamentais reconhecem a importância de melhorar a qualidade da educação em diferentes áreas na Amazônia.
\end{abstract}

Os resultados obtidos sobre as políticas educacionais desenvolvidas pela Secretaria Municipal de Educação de Belterra mostram, ainda que:

- A política educacional (local) foi planejada no sentido de atender às diretrizes da política macro de orientações de ordem internacional e nacional para: a questão da universalização do acesso ao ensino de qualidade; a dignificação do trabalho e valorização do magistério, e democratização da gestão educacional e da gestão escolar, voltadas principalmente, para o ensino fundamental. Porém, apesar de tais diretrizes, se correlacionarem, também com as necessidades educacionais locais, foi observado que a Semed enfrentou durante todas as gestões municipais, a complexidade de materializá-las no campo real. O que permite evidenciarmos a importância de investigações sobre aprendizagens institucionais exitosas, quanto à condução das políticas educacionais, que foram possíveis de "darem certo". 


\section{Referências}

ABREU, M. Educação Infantil no Brasil: legislação, matrículas, financiamentos e desafios. Estudo. Brasília, DF: Câmara dos Deputados, Consultora Legislativa da Área XV Educação, Cultura, Desporto, Ciência e Tecnologia, 2004.

ARAUJO, F. L. G. M. P. (Org.). Direito humano à educação na Amazônia: uma questão de justiça social. Belém (PA): Sociedade Paraense em Defesa dos Direitos Humanos, 2013. AZEVEDO, J. M. L. de; AGUIAR, M. A. Políticas de educação: concepções e programas. In: WITTMANN, L. C.; GRACINDO, R. V. (Coords.). O estado da arte em política e gestão da educação no Brasil: 1991 a 1997. Campinas (SP): Autores Associados; Brasília: Inep, 2001a. p. 43-51.

BELTERRA (Município). Relatório de Revitalização do Centro de Referência de Educação Ambiental - CEREA. Considerações IlonaGrunewald. Belterra: Secretaria Municipal de Educação, Cultura e Desporto, 2004.

BELTERRA (Município). Relatório de Atividades da Diretoria de Ensino. Belterra: Secretaria Municipal de Educação, Cultura e Desporto, 2006 a 2008.

BELTERRA (Município). Relatório do Sistema Gestor: período de 2010-2011-2012. Belterra: Secretaria Municipal de Educação, Cultura e Desporto, Setor de Estatística e Censo Escolar.

BLOG Belterra do Tapajós. Disponível em: <http://belterradotapajos.blogspot.com.br/>. Acesso em: 12 ago. 2014.

BRASIL. Constituição (1988). Constituição da República Federativa do Brasil. Diário Oficial [da] República Federativa do Brasil, Brasília, DF: Imprensa Nacional, n. 191-A, 5 out. 1988.

BRASIL. Lei no 9.394 de 20 de dezembro de 1996. Lei de Diretrizes e Bases da

Educação Nacional. Brasília, 1996a. Disponível em:
$<$ http://www.planalto.gov.br/ccivil_03/leis/19394.htm>. Acesso em: 02 nov. 2014.

BRASIL. Ministério do Meio Ambiente. Relatório da Fase 1 Plano de Educação Ambiental da Floresta Nacional do Tapajós 2001/2012. Brasília, DF: ProManejo, 2003. BRASIL. Ministério da Educação. Estudo exploratório sobre o professor brasileiro com base nos resultados do Censo Escolar da Educação Básica 2007. Brasília, DF: Instituto Nacional de Estudos e Pesquisas Educacionais Anísio Teixeira, 2009.

BRASIL. Ministério da Educação. Secretaria de Educação Básica. Diretrizes curriculares nacionais para a educação infantil. Brasília, DF: Secretaria de Educação Básica, 2010.

BRASIL, Presidência da República Federativa do. Decreto $\mathbf{n}^{0} \mathbf{7 . 3 5 2}$, de 4 de novembro de 2010. Dispõe sobre a política de educação do campo e o Programa Nacional de Educação na Reforma Agrária-PRONERA, 2010b. Disponível em: <http://www.planalto.gov.br/ccivil_03/_ato2007-2010/2010/decreto/d7352.htm $>$.

Acesso em 13.08.2015.

BRASIL. Ministério da Educação. Censo escolar 2012. Brasília, DF: Instituto Nacional de Estudos e Pesquisas Educacionais Anísio Teixeira, 2012.

CALDART, R. S. Primeira Conferência Nacional por uma Educação Básica no Campo. 4. ed. Petrópolis, RJ: Vozes, 2009.

CAMARGO, C. Sociedade e natureza nas ondas do rádio na Amazônia: representações e significados. Anais do XXIX Congresso Brasileiro de Ciências da Comunicação, da Intercom - Sociedade Brasileira de Estudos Interdisciplinares da Comunicação - UnB - 6 a 9 de setembro de 2006.2 Disponível em: $\langle$ http://www.intercom.org.br/papers/nacionais/2006/resumos/R0306-1.pdf $>$. Acesso em 02.09.2015 
CARDOSO, M. A.; JACOMELI, M. R. M. Considerações sobre as Escolas Multisseriadas: estado da arte. Revista de Educação Educere, Cascavel/PR, v. 5, n. 9, p. 267-290, jan./jun. 2010.

COLARES, A. A. Afirmação étnica e educação escolar indígena do povo Munduruku de Marituba (Belterra - Pará).Revista HISTEDBR On-line, Campinas, no 50 (especial), p. 99-122, mai. 2013. ISSN: 1676-258 100.

COSTA, F. de A. Capital estrangeiro e agricultura na Amazônia: a experiência da Ford Motor Company (1922-1945). 1981. Dissertação (Mestrado) - Escola Interamericana de Administração Pública, Fundação Getúlio Vargas, Rio de Janeiro, 1981.

GRANDIN, G. Fordlândia: Ascensão e queda da cidade esquecida de Henry Ford na selva.Tradução de Nivaldo Montingelli Jr. Rio de Janeiro: Rocco, 2010.

HAGE, S. M. (Org.) Educação do campo na Amazônia: retratos de realidade das escolas multisseriadas no Pará. Belém: Gutemberg, 2008.

IBGE. Instituto Brasileiro de Geografia e Estatística. Dados do Censo Cidades: Belterra. 2010. Disponível em: <www.cidades.ibge.gov.br>. Acesso em: 05 mai. 2014.

IBGE. Instituto Brasileiro de Geografia e Estatística. Dados do Censo Cidades: Belterra. 2015. Disponível em: <www.cidades.ibge.gov.br>. Acesso em: 10 ago. 2016.

LANE, M. Fotos dos grupos escolares de Henry Ford, 2011. Disponível em:< http://belterradotapajos.blogspot.com.br/search/label/Henry\%20Ford $>$. Acesso em 12.08.2015.

LOUREIRO, V. Educação e Sociedade nos últimos 60 anos. In: MENDES, Armando Dias. (Org.). Amazônia, Terra e Civilização: uma trajetória de 60 anos. Belém: Banco da Amazônia, 2004.

PARÁ (Estado). Secretaria Executiva de Educação Básica. $2^{\circ}$ Caderno da Educação Básica do Estado do Pará. Belém, $2008 b$.

PARÁ (Estado). Secretaria Executiva de Estado de Planejamento, Orçamento e Finanças. Instituto de Desenvolvimento Econômico, Social e Ambiental do Pará. Estatística Municipal: Belterra. Belém, 2013-2014.

PARÁ (Estado). Fundação Amazônia Paraense de Amparo à Pesquisa - Fapespa. Diagnóstico Socioeconômico e Ambiental da Região de Integração do Baixo Amazonas. Belém, 2015. Disponível em: <http://www.fapespa.pa.gov.br>. Acesso em 10.12.2014.

PEREIRA, J. C. M. Os modos de vida na cidade: Belterra, um estudo de caso na Amazônia Brasileira. 256f. 2012. Tese (Doutorado) - Instituto de Filosofia e Ciências Humanas, Universidade do Estado do Rio de Janeiro, Rio de Janeiro, 2012.

PEREZ, J. R. R. Por que pesquisar implementação de políticas educacionais atualmente?

Revista Educação e Sociedade, Campinas, v. 31, n. 113, p. 1179-1193, out.-dez. 2010. Disponível em: $<$ http://www.cedes.unicamp.br $>$. Acesso em 12.08.2014.

PRADO, E. C. do. Um olhar avaliativo sobre o MOVA-Regional no ABCD Paulista: dos movimentos populares dos anos de 60 à perspectiva neoliberal. 2007. Tese (Doutorado em Educação Escolar) - Faculdade de Ciências e Letras de Araraquara, Universidade Estadual Paulista, Araraquara, SP, 2007.

ROMANELLI, O. de. O. História da educação no Brasil (1930-1973). 8. ed. Petrópolis, RJ: Vozes, 1986.

SANTOS, O. Belterra: a sua história.Santarém/PA: Instituto Cultural Boanerges Sena, 2004.

SAVIANI, D. O trabalho como princípio educativo frente às novas tecnologias. In: FERRETTI, C. J. (Org.). Novas tecnologias, trabalho e educação: um debate multidisciplinar. 6. ed. Petrópolis, RJ: Vozes, 2000. 
SAVIANI. D. O legado educacional do "longo século XX" brasileiro. In: .O legado educacional do século XX no Brasil. 2. ed. Campinas, SP: Autores Associados, 2006. (Educação Contemporânea).

SAVIANI, D. Direito à educação e inversão do conceito: destaques. Revista Profissão Docente, Uberaba, v. 11, n. 23, p. 45-58, jan/jul. 2011.

SENA, C. Fordlândia: breve relato da presença americana na Amazônia. Cad. hist. ciênc., vol. 4, n. 2, pp. 89-108, 2008.

XIMENES-ROCHA, S. H.; COLARES, M. L. I. S. (Orgs.). Formação de Professores: Pesquisa com ênfase na escola do campo. Curitiba: CRV, 2012.

\footnotetext{
${ }^{1}$ Mestre em Educação pela Universidade Federal do Oeste do Pará.Pedagoga na Universidade Federal do Oeste do Pará (UFOPA), na Pró-reitoria de Ensino de Graduação. Integrante do Grupo de Estudos e Pesquisas História, Sociedade e Educação no Brasil. HISTEDBR/UFOPA.Email: angelashalon@hotmail.com

${ }^{2}$ Doutora em Educação. Professorado Programa de Pós-graduação da Universidade Federal do Oeste do Pará/UFOPA. E-mail: maria.colares@ufopa.edu.br

${ }^{3}$ Segundo Grandin (2010, p. 84), Ford é um nome presente no cotidiano contemporâneo desde 1903, após a fundação da Ford Motor Company, em Detroit. Fordismo tornou-se um conceito das ciências sociais para caracterizar um período e uma prática da sociedade industrial do século XX, orientada pela produção em linha de montagem e pelo consumo de massa, através de uma política salarial de trabalhadores e constituição de mercado aquisitivo.

${ }^{4}$ No caso do município de Belterra, segundo Colares (2013, p. 101), após o final da década de 1990, eclode o movimento de reelaboração da identidade indígena de parte das populações que se encontram na área de duas reservas de proteção ambiental: Floresta Nacional do Tapajós (Flona Tapajós), criada em 1974, e Reserva Extrativista Tapajós-Arapiuns (Resex Tapajós-Arapiuns), criada em 1998, ambas situadas em uma área que o IBGE denomina como microrregião do Médio Amazonas Paraense, também identificada como Baixo Amazonas ou Região do Baixo Rio Tapajós.

${ }^{5}$ Costa (1981), Lane (2011), Santos (2004), Sena (2008), Pereira (2012).

${ }^{6}$ Dados referentes aos depoimentos de (ex-) servidores que atuaram na primeira gestão da Semed, e também dos dados coletados com Entrevistada A.
}

Recebido: novembro/16 Aprovado: dezembro/16 